( 2022 , The Authors. Published by Elsevier Inc. and Fass Inc. on behalf of the American Dairy Science Association ${ }^{\circledR}$. This is an open access article under the CC BY license (http://creativecommons.org/licenses/by/4.0/).

\title{
An approach to improve the baking properties and determine the onset of browning in fat-free mozzarella cheese
}

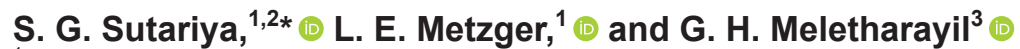 \\ ${ }^{1}$ Dairy and Food Science Department, South Dakota State University, Brookings 57007 \\ ${ }^{2}$ Agropur, US Operations, Lake Norden, SD 57248 \\ ${ }^{3}$ Dairy Management Inc., Rosemont, IL 60018
}

\begin{abstract}
Compared with low-moisture part-skim mozzarella and mozzarella cheese, bake performance of low-fat and fat-free mozzarella on pizza has a lot to desire. We hypothesized that a water-soaking pretreatment step of low-fat and fat-free cheese shreds before baking would improve pizza baking performance. The study also examined the correlation of the onset of cheese browning with the rate of moisture loss, changes in cheese surface temperature, and 3-dimensional (3D) plot $\mathrm{L}^{*} \mathrm{a}^{*} \mathrm{~b}^{*}$ CIELAB color analysis. The pretreatment of soaking cheese shreds in water improved the baking properties of fat-free mozzarella cheese on pizza. Compared with the control sample, which demonstrated significant shred identity, poor shred melt, fusion, and stretch during a pizza bake with fat-free mozzarella, the soaked cheese (SC) sample demonstrated satisfactory cheese melt, fusion, and stretch. In addition, the SC sample had desired browning as opposed to the control sample's excessive browning. The additional moisture from the soaking pretreatment aided in delaying the onset of cheese browning in the SC sample when compared with the control sample. For both the control and SC samples, there was a strong correlation between the onset of cheese browning with the peak of moistureloss rate, and an increase in cheese surface temperature $\left(>100^{\circ} \mathrm{C}\right)$. The color analysis of the 3D plot confirmed the relationship between the onset of cheese browning and the shift in $\mathrm{L}^{*}$ (lightness), $\mathrm{a}^{*}$ (red-green color), and $b^{*}$ (blue-yellow) values. According to the study's findings, soaking cheese shreds before baking can help improve bake performance on pizza. Furthermore, 3 measurement tools used in the study, (1) moisture-loss rate, (2) cheese surface temperature, and (3) 3D plot CIELAB color, were useful in determining the onset of cheese browning and can be applied to different in-
\end{abstract}

\footnotetext{
Received August 21, 2021.

Accepted October 31, 2021.

*Corresponding author: sutariyasuresh83@gmail.com
}

tervention strategies to control cheese browning during pizza baking.

Key words: fat-free mozzarella cheese, browning, 3D plot CIELAB color, cheese surface temperature, moisture-loss rate

\section{INTRODUCTION}

Given the consumer's ever-changing lifestyle and the growing demand for low-fat foods, there is a need to develop low-fat and fat-free mozzarella cheese with sensory properties similar to low-moisture part-skim mozzarella and mozzarella cheese. Because $\sim 75 \%$ of the mozzarella cheese produced in the United States is used as a pizza ingredient, the sensory attributes of mozzarella cheese on pizza can influence overall liking. Some of the desired functionality of mozzarella cheese on pizza after baking are complete melting, shred fusion, desired browning, and some free oil on the surface (Ah and Tagalpallewar, 2017). Mozzarella cheese with a lower fat content than low-moisture part-skim mozzarella performs poorly during the baking process and results in poor melt and shred fusion, and higher browning (Rudan and Barbano, 1998; Wadhwani et al., 2011). Baking of fat-free mozzarella cheese on a pizza is challenging due to its low moisture-to-protein ratio. Fat and moisture content of mozzarella cheese is an important attribute that improves its bake performance on a pizza (Ah and Tagalpallewar, 2017).

Several studies have been carried out to improve the bake performance of fat-free and low-fat mozzarella cheese. The influence of surface-free oil on the melting and browning behavior of fat-free and reduced-fat mozzarella cheese during pizza baking was investigated by Rudan and Barbano (1998). The studies revealed that prevention of dry skin formation on the surface of cheese shreds during the bake process is critical to avoid defects observed during the baking of fat-free mozzarella cheese. The use of hydrophobic surface coating (cooking oil) reduced browning and improved melt. Increasing the moisture-to-protein ratio is also suggested to improve bake performance of low-fat moz- 
zarella (Merrill et al., 1994; Fife et al., 1996). These reported improvements in bake performance were linked to preventing excessive drying and browning by reducing moisture loss during baking and maintaining an adequate moisture content on the cheese surface. To optimize bake performance of low-fat and fat-free mozzarella shreds, we recommend a new method of shred soaking before baking. It was hypothesized that soaking fat-free mozzarella cheese shreds in refrigerated $\mathrm{NaCl}$ solution overnight before baking would improve cheese bake performance by increasing protein hydration and maintaining an adequate moisture content on the cheese surface during baking. The proposed method also has the added benefit of being cost-effective and clean label.

We also evaluated the correlation between moistureloss rate, cheese surface temperature and 3-dimensional (3D) plot CIELAB color analysis with the onset of cheese browning. Earlier studies measured the moisture loss (Rudan and Barbano, 1998; Dumas and Mittal, 2002; Wadhwani et al., 2011) and cheese temperature (Kindstedt et al., 1989; Dumas and Mittal, 2002; Ma et al., 2014) during baking. However, no study has investigated the relationship between onset of cheese browning, rate of moisture loss, and the cheese surface temperature during baking. Similarly, a computer vision system and image analysis was used by researchers to study various quality parameters of pizza toppings (Sun, 2000; Wang and Sun, 2002a,b,c, 2003) and quantification of pizza baking properties (Ma et al., 2013a,b, 2014); however, no attempt has been made to study the relationship between changes in $3 \mathrm{D}$ plot color analysis and the onset of cheese browning. Therefore, the objectives of the present study were as follows: (1) investigate the effectiveness of soaking fat-free cheese shreds in refrigerated salt solution for improving the baking properties during pizza bake and (2) investigate the correlation between moisture-loss rate, cheese surface temperature, and 3D plot color analysis to the onset of cheese browning during pizza bake.

\section{MATERIALS AND METHODS}

\section{Sample Preparation for Pizza Bake}

Fat-free shredded mozzarella (Great Value) was purchased from a retail store (Walmart, Brooking, SD). The shredded cheese was divided into 2 equal parts of $200 \mathrm{~g}$ each, which were labeled as control and soaked cheese (SC). For the SC sample, $100 \mathrm{~g}$ of cheese shreds were soaked in $50 \mathrm{~g}$ of salt solution for $8 \mathrm{~h}$ in a refrigerator maintained at $\sim 4.5^{\circ} \mathrm{C}$. The salt solution was prepared from deionized water containing $2 \%$ (wt/wt) $\mathrm{NaCl}$ with $\mathrm{pH}$ adjusted to 5.25 using lactic acid. At the end of $8 \mathrm{~h}$, cheese shreds absorbed all the water. The moisture content of the SC sample increased to 69.7 $\pm 0.005 \%( \pm \mathrm{SE})$, from $54.42 \pm 0.72 \%$ in the control sample. Based on our preliminary findings, we chose a 2:1 ratio of cheese to salt solution in the SC sample (100 $\mathrm{g}$ of cheese soaked in $50 \mathrm{~g}$ of cold salt solution). In preliminary studies, we tested the following 4 different ratios of cheese to salt solution: $4: 1,2: 1,1.33: 1$, and $1: 1$. Of these 4 ratios, 2:1 was shown to provide optimum baking properties.

\section{Soaked Cheese Shred Stability During Storage}

To investigate the SC shred stability during storage, $1,000 \mathrm{~g}$ of cheese shreds were soaked in $500 \mathrm{~g}$ of refrigerated salt solution. These shreds were stored in a refrigerator maintained at $\sim 4.5^{\circ} \mathrm{C}$ for up to $72 \mathrm{~h}$. Shreds were evaluated for clumping at the intervals of 12,24 , 48 , and $72 \mathrm{~h}$. After $72 \mathrm{~h}$ of refrigerated storage, shreds were frozen for $4 \mathrm{~d}$ followed by thawing for $7 \mathrm{~d}$ under refrigeration conditions $\left(\sim 4.5^{\circ} \mathrm{C}\right)$. Thawed shreds were visually evaluated for clumping.

\section{Pizza Baking}

The melting, browning, and stretch characteristics of control and SC cheese samples were compared in a pizza baking test. Pizza was prepared using a slightly modified method (Rudan and Barbano, 1998; Wadhwani et al., 2011) by evenly spreading $70 \mathrm{~g}$ of pizza sauce (Roma food) on a 12-inch (132 g) thick crust pizza base (Alive and Kickin Pizza crust; A\&K). To avoid any variation between 2 different pizza bases, both the control and SC cheeses were baked on the same pizza base. One-half of the pizza base was evenly spread with $110 \mathrm{~g}$ of control cheese, and the other half was evenly spread with $165 \mathrm{~g}$ of SC cheese (110 g of cheese soaked in $55 \mathrm{~g}$ of salt solution, a 2:1 ratio). The pizza was baked for 5 min at $246^{\circ} \mathrm{C}$ in a forced air conveyor oven (model PS520E, Middleby Marshall). The images of the pizza before and after baking were taken with an iPhone 8 camera (model MQ722LL/A, software version 13.6.1). When the cheese cooled to $77^{\circ} \mathrm{C}$, a fork test was performed to evaluate cheese stretch. A stainless-steel fork was inserted into the cheese and vertically lifted to compare the stretch between control and SC cheese.

\section{Rate of Moisture Loss During Simulated Baking}

The rate of moisture loss in both control and SC cheese was determined to evaluate the relationship between the onset of cheese browning and the rate of moisture loss. On an aluminum pan (VWR Scientific Products), $15 \mathrm{~g}$ of control cheese and $22.5 \mathrm{~g}$ of $\mathrm{SC}$ 

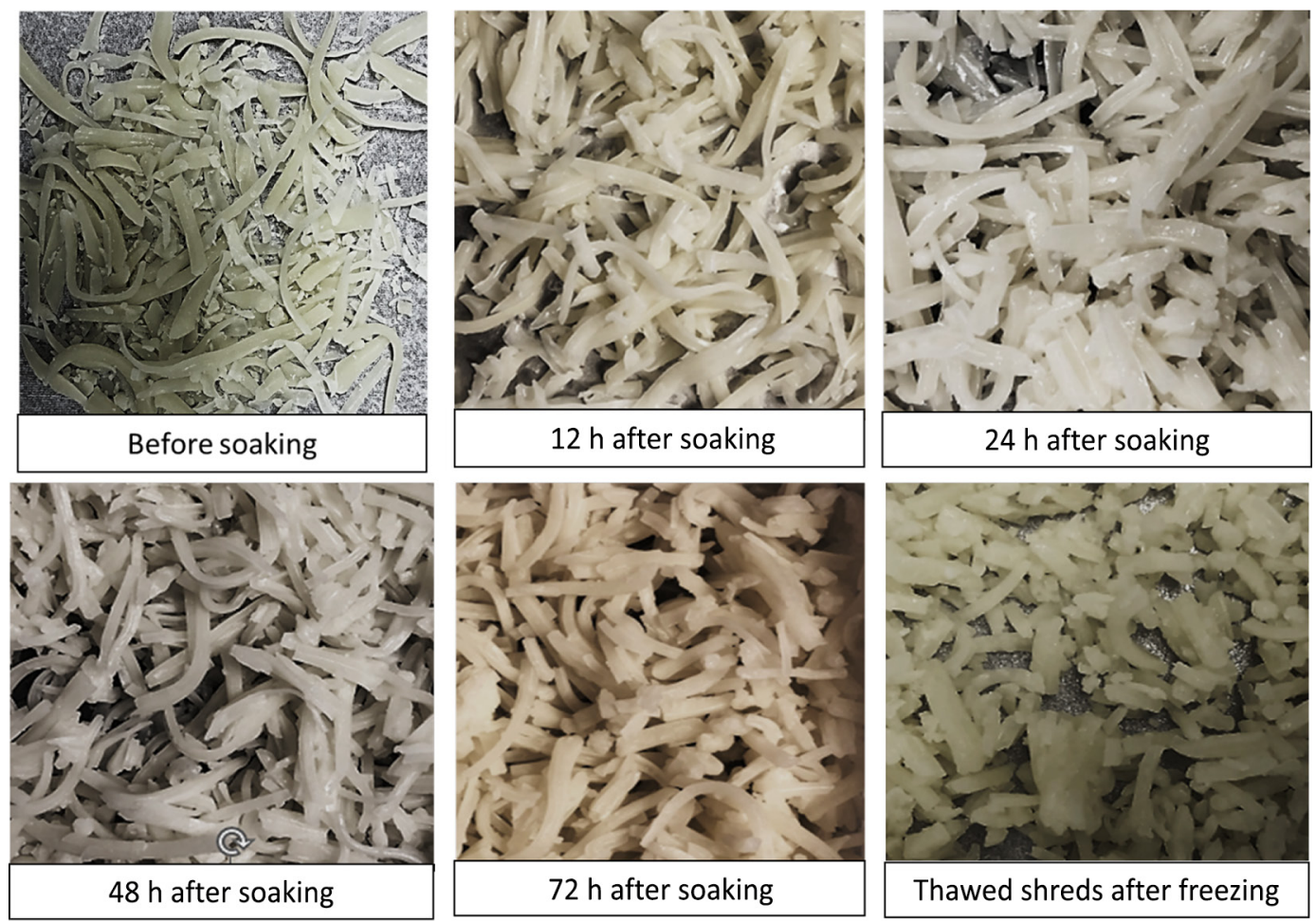

Figure 1. Shred stability of soaked cheese (SC) during refrigerated storage and thawed shreds after frozen storage.

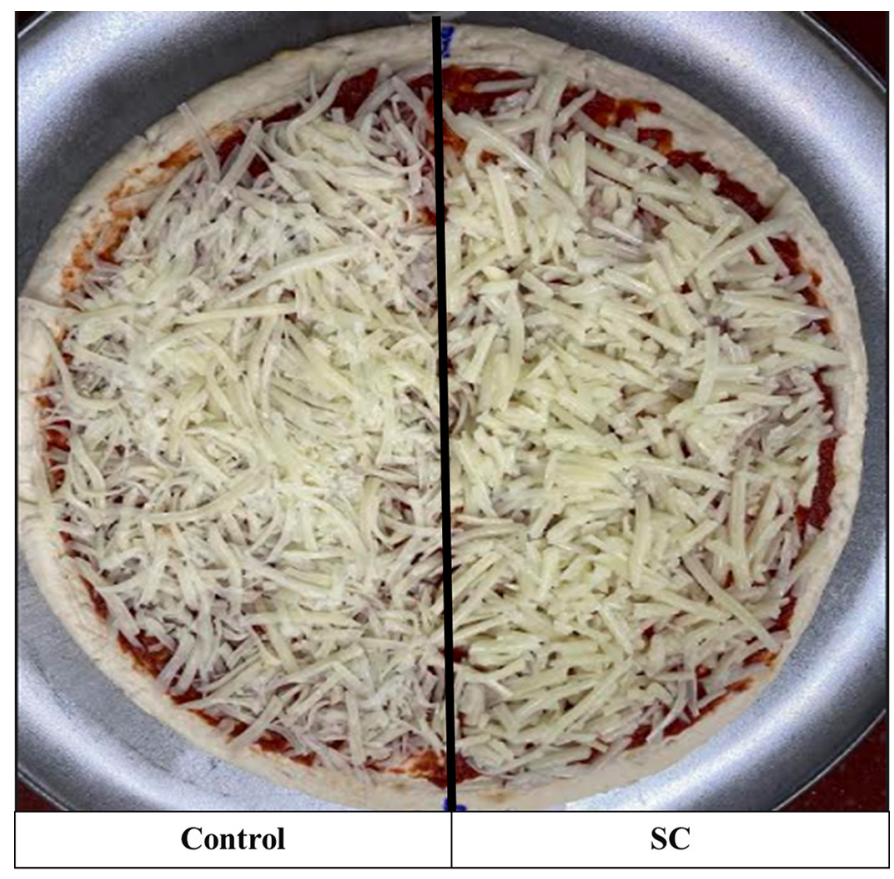

Figure 2. Image of pizza bake preparation before baking with comparison of control and soaked cheese (SC) shred appearance on a pizza pie. cheese (15 $\mathrm{g}$ of cheese soaked in $7.5 \mathrm{~g}$ of water, $2: 1$ ratio) were weighed and spread. A moisture balance (MB200; Ohaus) set at $205^{\circ} \mathrm{C}$ for a 10 -min test period was used to investigate the moisture-loss rate. The maximum temperature operating limit of the moisture balance was $205^{\circ} \mathrm{C}$, which was the temperature at which the simulated test was performed rather than the actual baking temperature of $246^{\circ} \mathrm{C}$. However, the data from simulated baking should still be useful in understanding the relationship between the rate of moisture loss and the onset of cheese browning. Moisture loss was measured every $30 \mathrm{~s}$ for up to $10 \mathrm{~min}$ (expressed as the difference in weight between 2 consecutive readings). Tests were carried out in triplicate, and the time at which the highest moisture-loss rate occurred for both the control and SC cheese samples was recorded.

\section{Cheese Surface Temperature During Simulated Baking}

Simulated baking of control and SC cheese was performed to investigate the relationship between changes in cheese surface temperature and the onset of browning. To measure the cheese surface temperature during baking, an infrared thermometer (NUB8500H, Nubee) was mounted above the moisture balance at a fixed 


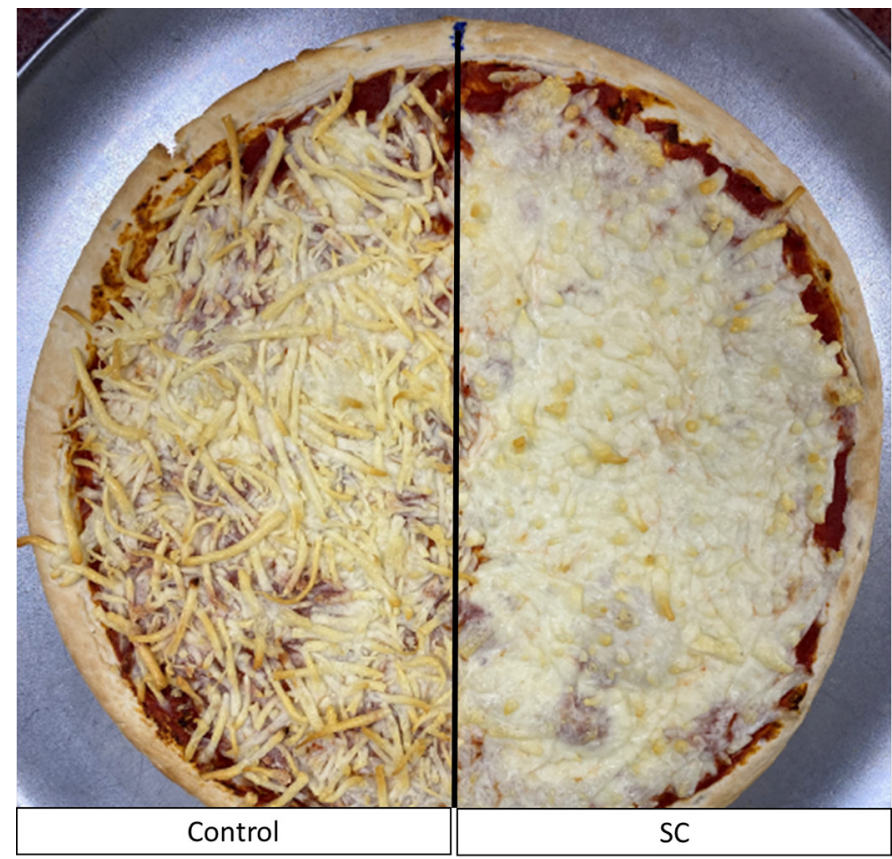

Figure 3. Baked pizza with control and soaked cheese (SC) showing the differences in melt characteristics, shred identity, and browning between the two.

distance (as recommended by the manufacturer) with the infrared beam pointing at the center of the cheese spread over aluminum pan. The surface temperature of the cheese was measured every $30 \mathrm{~s}$ for up to $10 \mathrm{~min}$.

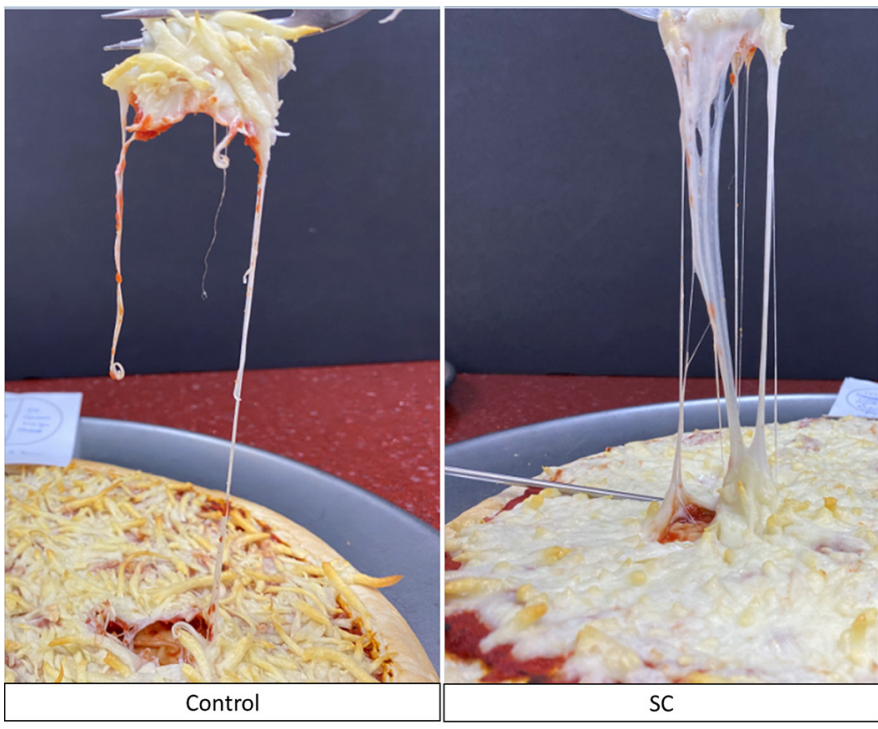

Figure 4. Image of pizza bake after baking with comparison of control and soaked cheese (SC). Stretch by fork test is shown.

\section{Correlation Between Rate of Moisture Loss, Cheese Surface Temperature, and Onset of Browning}

To study the correlation between rate of moisture loss, cheese surface temperature, and onset of browning, the images of cheese samples were captured (iPhone 8) every $60 \mathrm{~s}$ for up to 10 min during simulated baking of the control and SC cheese samples. The times when the visual onset of browning occurred for both the control

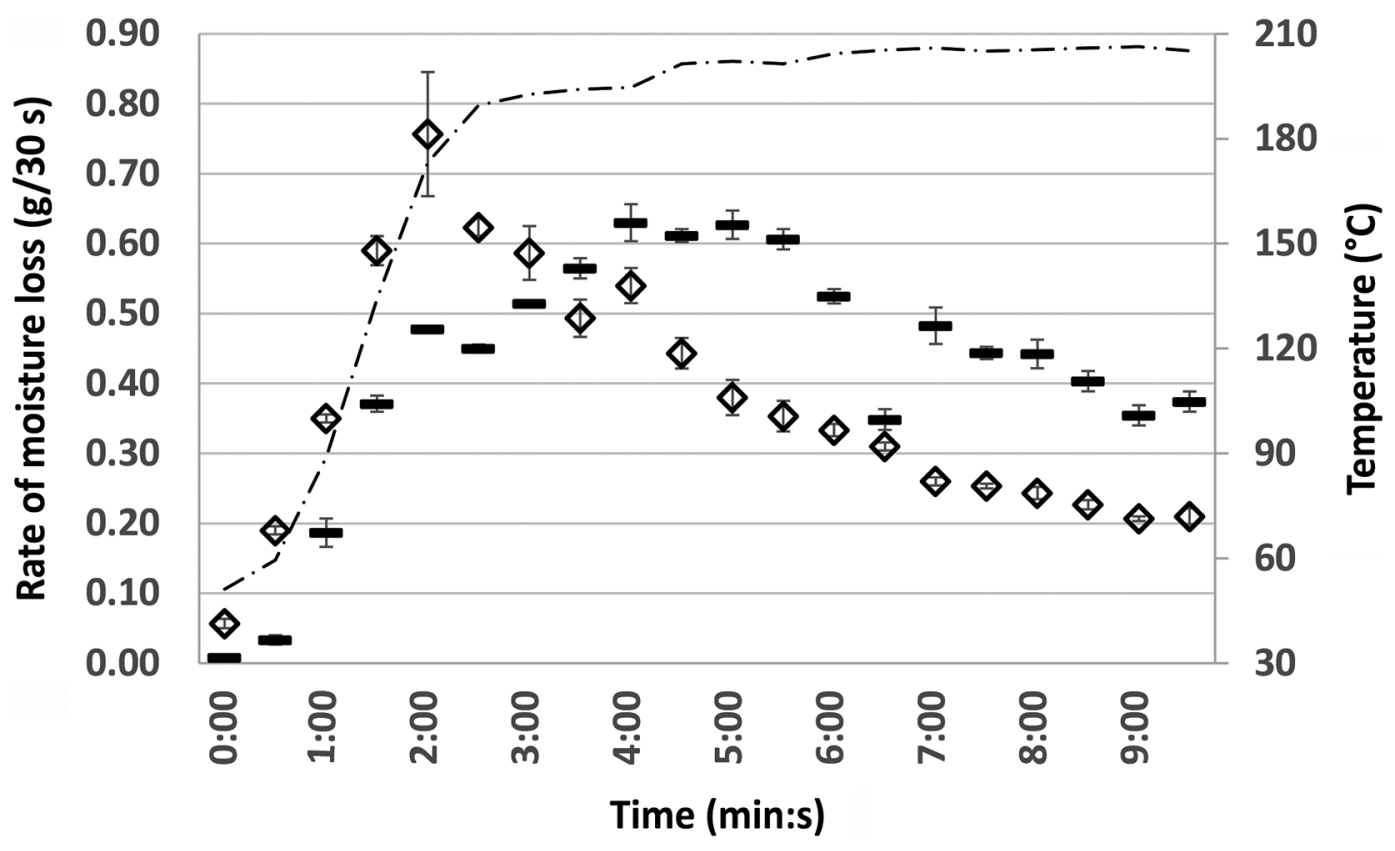

Figure 5. Moisture loss rate of $(\diamond)$ control cheese sample and $(\mathbf{-})$ soaked cheese sample (SC) and (-.-) heating air temperature. Values are means of triplicate experiment values, with the SEM indicated by vertical error bars. 
and SC samples were determined based on visual inspection of these images. The correlation between the rate of moisture loss, the cheese surface temperature, and the onset of browning was determined by comparing these data with the time when visual onset of browning occurred.

\section{D Plot CIELAB Color Analysis and Frequency Distribution for $L^{*}$, $a^{*}$, and $b^{*}$ Values}

The images captured during simulated pizza baking were analyzed for $3 \mathrm{D}$ plot $\mathrm{L}^{*}$ (lightness), a* (redgreen color), and $\mathrm{b}^{*}$ (blue-yellow color) color space with weighted frequency display mode using software (ImageJ 1.53a, Wayne Rasband, National Institutes of Health) with a plugin (Color Inspector 3D, Kai Uwe Barthel, Internationale Medieninformatik). The area of the image chosen for color analysis contained only the cheese portion, with the exposed aluminum base left out. The images obtained using Image J software were further processed with GIMP 2.8.8 software (GNU
Image Manipulation Program) to improve the image visibility by increasing the image brightness to $25 \%$ and contrast to $90 \%$.

Color Inspector 3D plugins for ImageJ can offer 3D color plots. The software does not, however, generate $\mathrm{L}^{*}, \mathrm{a}^{*}$, and $\mathrm{b}^{*}$ data in the form of a frequency distribution table. To overcome this limitation, we manually built a $L^{*}, a^{*}$, and $b^{*}$ data frequency distribution table by tabulating the values from 25 selected representative points from a $3 \mathrm{D}$ color plot. For each $\mathrm{L}^{*}, \mathrm{a}^{*}$, and $\mathrm{b}^{*}$ value for $0,1,2,3,4$, and 5 min of simulated bake time, frequency distribution graphs for both control and SC were constructed using frequency distribution data. Tests were carried out in triplicate.

\section{RESULTS AND DISCUSSION}

\section{Soaked Shred Stability During Storage}

The SC cheese shreds exhibited no substantial clumping up to $72 \mathrm{~h}$ of refrigerated storage. Soft clumps

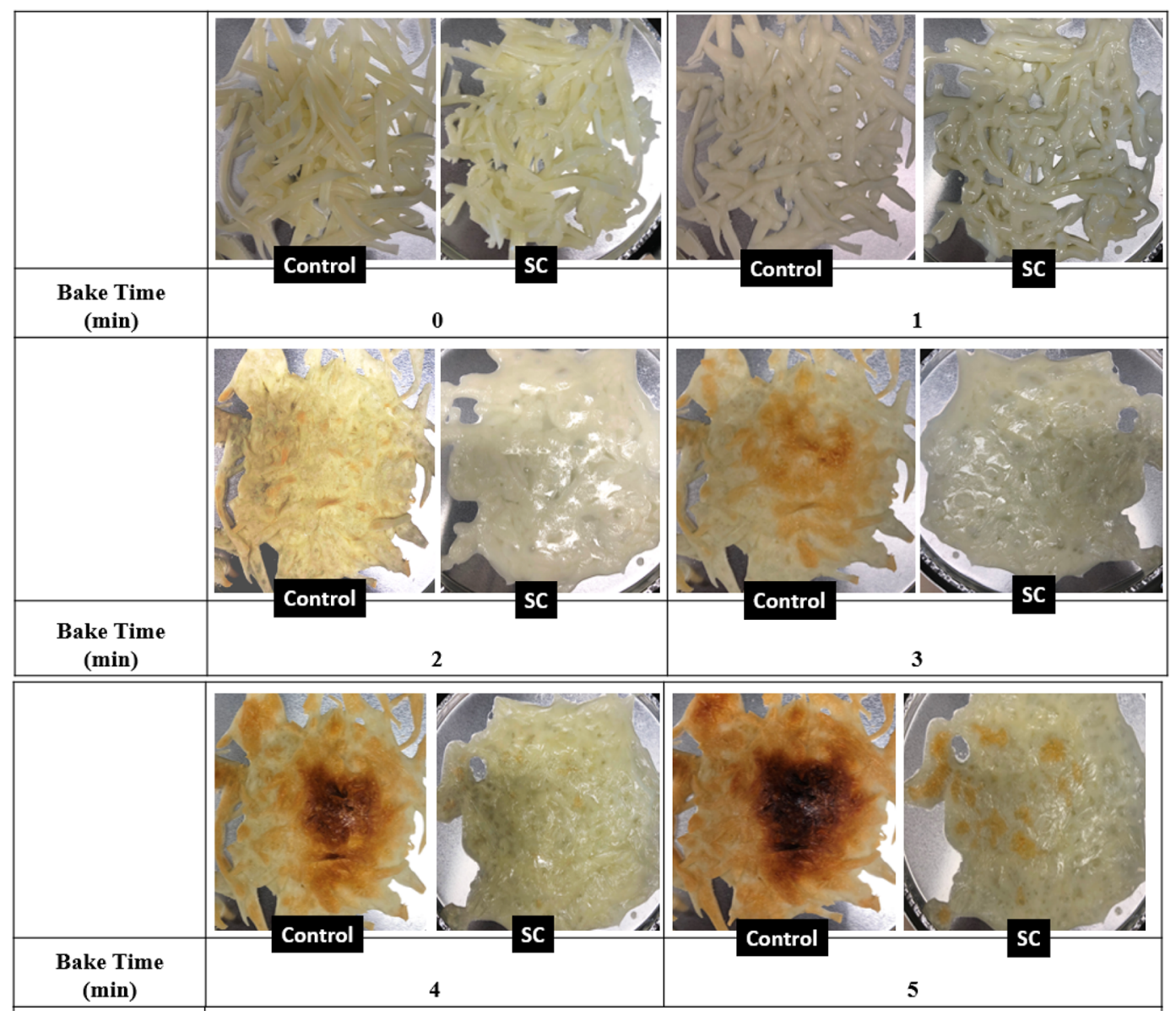

Figure 6. Visual onset of cheese browning during simulated baking in moisture balance set at $205^{\circ} \mathrm{C}$ with the control cheese sample and soaked cheese sample (SC). 
were easily separated by hand. Similarly, clumps from thawed SC shreds disintegrated by hand, but an increased shattering tendency was observed (Figure 1).

\section{Pizza Preparation and Baking}

Pizza Preparation. Before baking, control cheese shreds on a pizza pie appeared dry with some visible fines, whereas shreds in the SC sample appeared to have an increased volume and wet appearance with minimal fines due to soaking (Figure 2). The majority of these fines in the control appeared to be anticake (potato starch) powder, and its solubilization with soaking salted water may have resulted in lower level of fines in the SC sample. Despite the increased moisture of the SC sample, the shreds did not clump, which is important for handling and uniform distribution of cheese shreds on a pizza pie (Figure 2). Cheese manufacturers limit the moisture content of mozzarella cheese below $60 \%$ (wt/wt) to prevent the cheese from sticking to shredder blades during shredding and excessive clumping during storage (Ah and Tagalpallewar, 2017). The intervention to increase moisture content of cheese (through soaking) before the pizza baking process eliminates the shredding and storage issues associated with higher moisture cheese blocks and shreds.

Pizza Baking. In the current set of experiments, the control cheese sample showed a lack of shred fu- sion, as well as poor melting and increased browning (Figure 3). The SC samples exhibited very little shred identity, very good melting, and very little browning (Figure 3). The shred identity and poor melting in the control sample indicated that the cheese shred surface began to dry before the shreds could reach a temperature at which they could melt and fuse together (Figure 3). This dry crust formation could act as a barrier, preventing moisture migration from the center of the shreds to the surface, resulting in a loss of protective effect against browning (Rudan and Barbano, 1998). When compared with a control sample with a poor melt, proper melting of SC samples resulted in a better stretch (Figure 4). The additional moisture in the SC sample aided in slowing the moisture loss (Figure 5) from the cheese surface during the pizza bake, preventing dry brown skin formation on individual cheese shreds before they could melt and fuse together (Figure 3). These SC shreds were able to melt, flow, and fuse together in the absence of dry skin formation. Better melting and fusion led to excellent cheese stretching (Figure 4). Although the use of $100 \%$ fatfree mozzarella cheese on pizza is limited by its poor baking properties and flavor attributes, the soaking method proposed in our study would allow fat-free mozzarella cheese to partially replace low-moisture part-skim or whole milk mozzarella in pizza without affecting consumer acceptability.

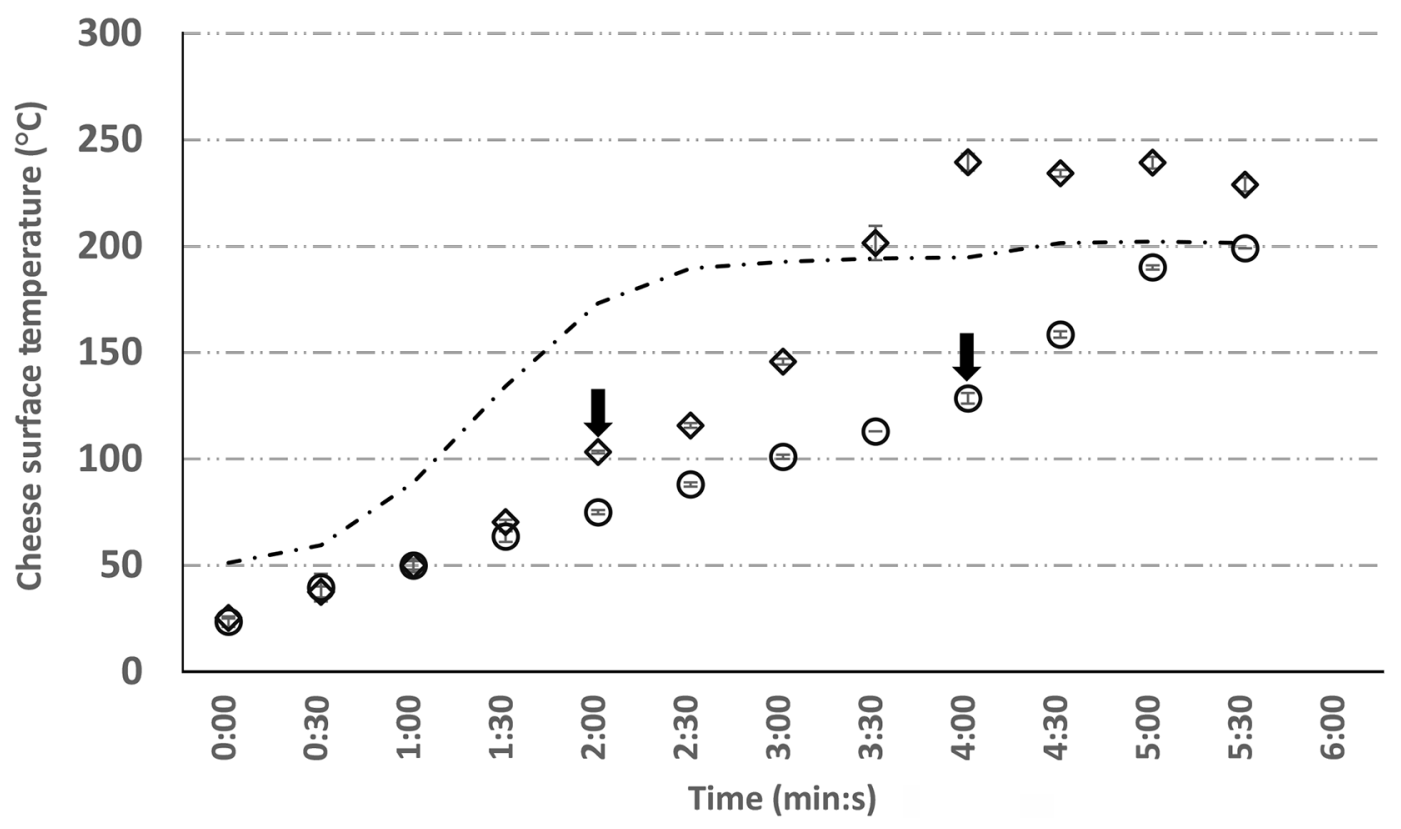

Figure 7. Cheese surface temperature during baking in moisture balance set at $205^{\circ} \mathrm{C}:(\diamond)$ control cheese sample, $(\mathrm{O})$ soaked cheese sample (SC), ( - - ) heating air temperature. Times at which onset of browning was observed are indicated by arrows. Values are means of triplicate experiment values, with the SEM indicated by vertical error bars. 


\section{Correlation Between Rate of Moisture Loss and Onset of Browning}

During the initial bake period, the rate of moisture loss in the control sample was higher than in the SC sample until it reached peak. The rate of moisture loss in the control sample peaked in 2 min, whereas the SC sample took approximately $4 \mathrm{~min}$ to reach the peak (approximately twice as long as the control; Figure 5). In comparison to the $\mathrm{SC}$ sample, the rate of moisture loss in the control sample fell sharply after the peak point and remained lower for the remainder of the baking period (Figure 5). According to the images captured during the simulated baking (Figure 6, control
$2 \mathrm{~min}$ ), the onset of cheese browning for the control sample coincided with the peak of moisture loss rate at 2 min of baking, confirming the start of the formation of dry crust on the cheese shred surface. The dry crust on the cheese shreds restricted moisture migration from the shred center to the surface and further evaporation from the cheese shred surface. This restricted moisture migration resulted in increased cheese browning at 3 min of baking and progressive cheese burning with a large blister at 4 and 5 min of baking (Figure 6 ). These images also demonstrated the effect of rapid moisture loss and dry crust formation on shred identity, as well as poor cheese shred melting and fusion in the control sample.

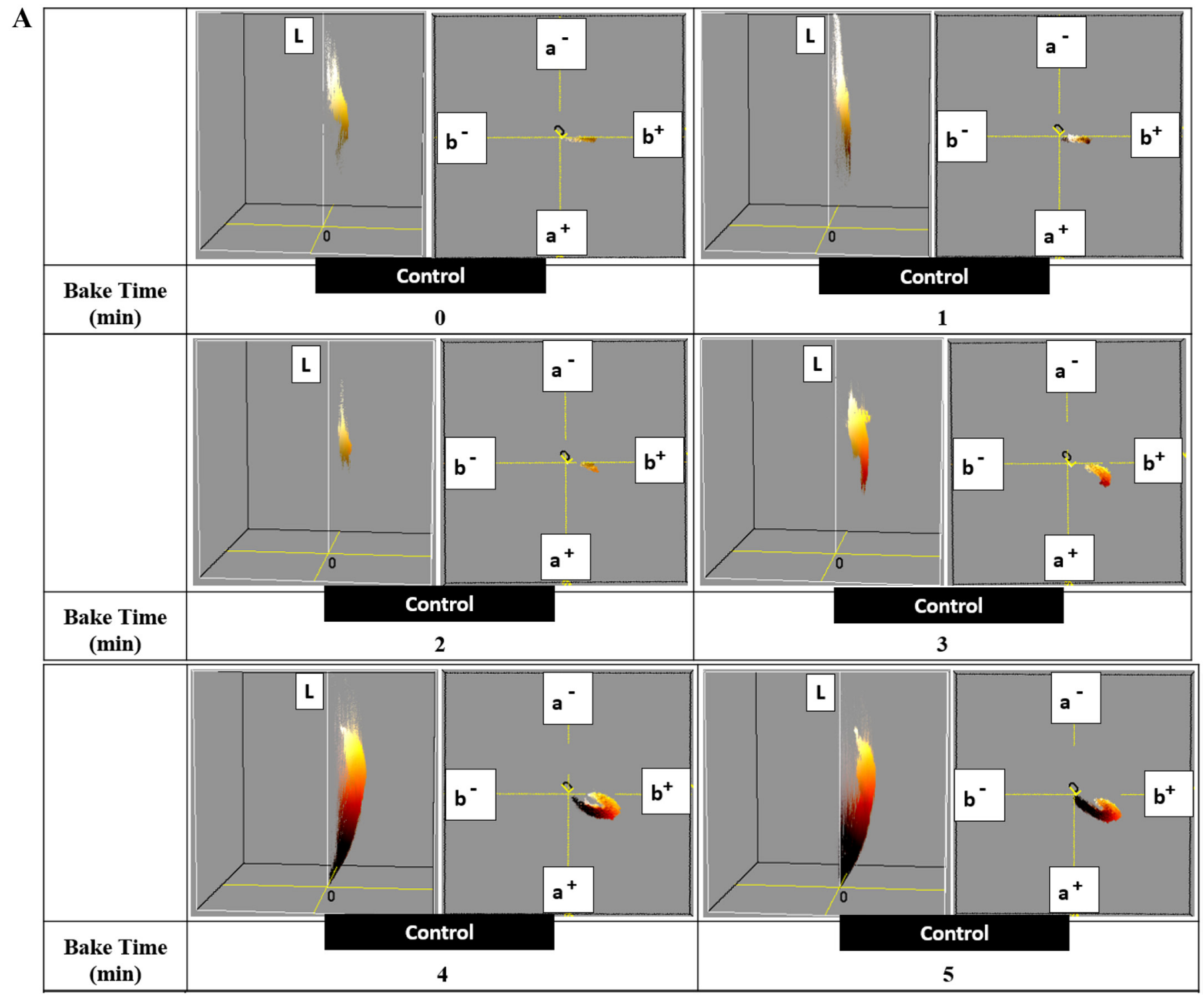

Figure 8. Three-dimensional Inspector Color analysis images, in the $\mathrm{L}^{*}$ (lightness) and a* (red-green color) and b* (blue-yellow color) planes obtained for control cheese (A) and soaked cheese (SC; B) samples during simulated cheese baking for $0,1,2,3,4$, and 5 min. 
The images captured during baking (Figure 6) for the SC sample showed the onset of cheese melt at 1 min, complete fusion of melted cheese at 2 and $3 \mathrm{~min}$, and the onset of very faint cheese browning at $4 \mathrm{~min}$. Lower rate of moisture loss until peak at $4 \mathrm{~min}$ and plateau in rate of moisture loss between 4 and $5.5 \mathrm{~min}$ indicated constant migration of moisture from cheese shred center to surface, which helped in maintaining sufficient amount of moisture at the surface. This protected against dry crust formation and allowed cheese shreds to melt and fuse together with little browning.

The time when the moisture-loss rate for both the control and SC samples reached its peak coincided with the time when the visual onset of browning occurred; thus, this method of measuring a peak in moisture-loss rate could be useful in detecting the start of cheese browning during baking. Any intervention strategy to control browning can be applied at this point.

\section{Correlation Between Cheese Surface Temperature and Onset of Browning During Baking}

Both the control and SC samples showed a steady rise in surface temperature during the first $90 \mathrm{~s}$ of baking (Figure 7). The surface temperature of the control sample increased rapidly after $90 \mathrm{~s}$ in comparison to
B

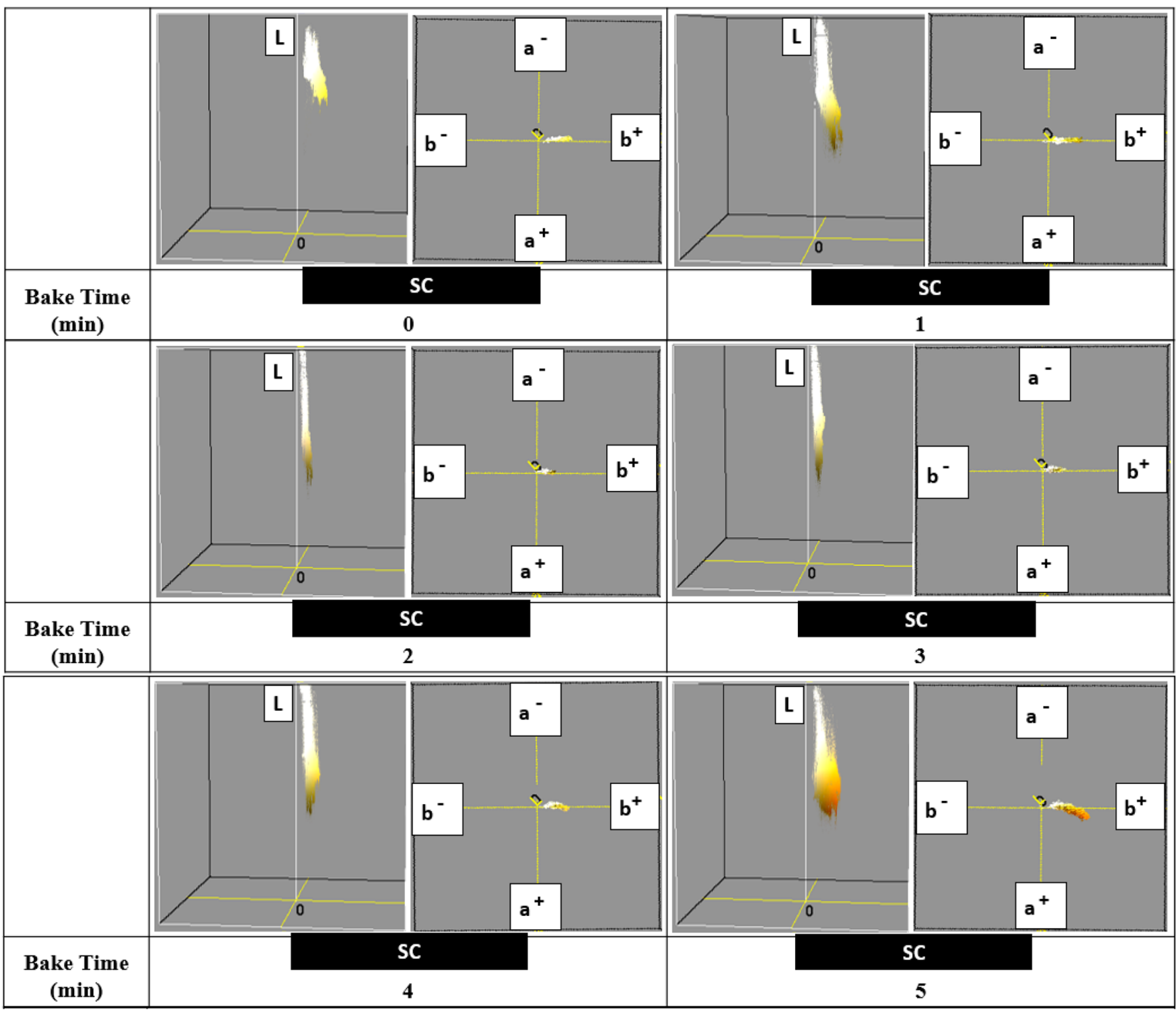

Figure 8. Three-dimensional Inspector Color analysis images, in the $\mathrm{L}^{*}$ (lightness) and a* (red-green color) and b* (blue-yellow color) planes obtained for control cheese (A) and soaked cheese (SC; B) samples during simulated cheese baking for 0, 1, 2, 3, 4, and 5 min. 


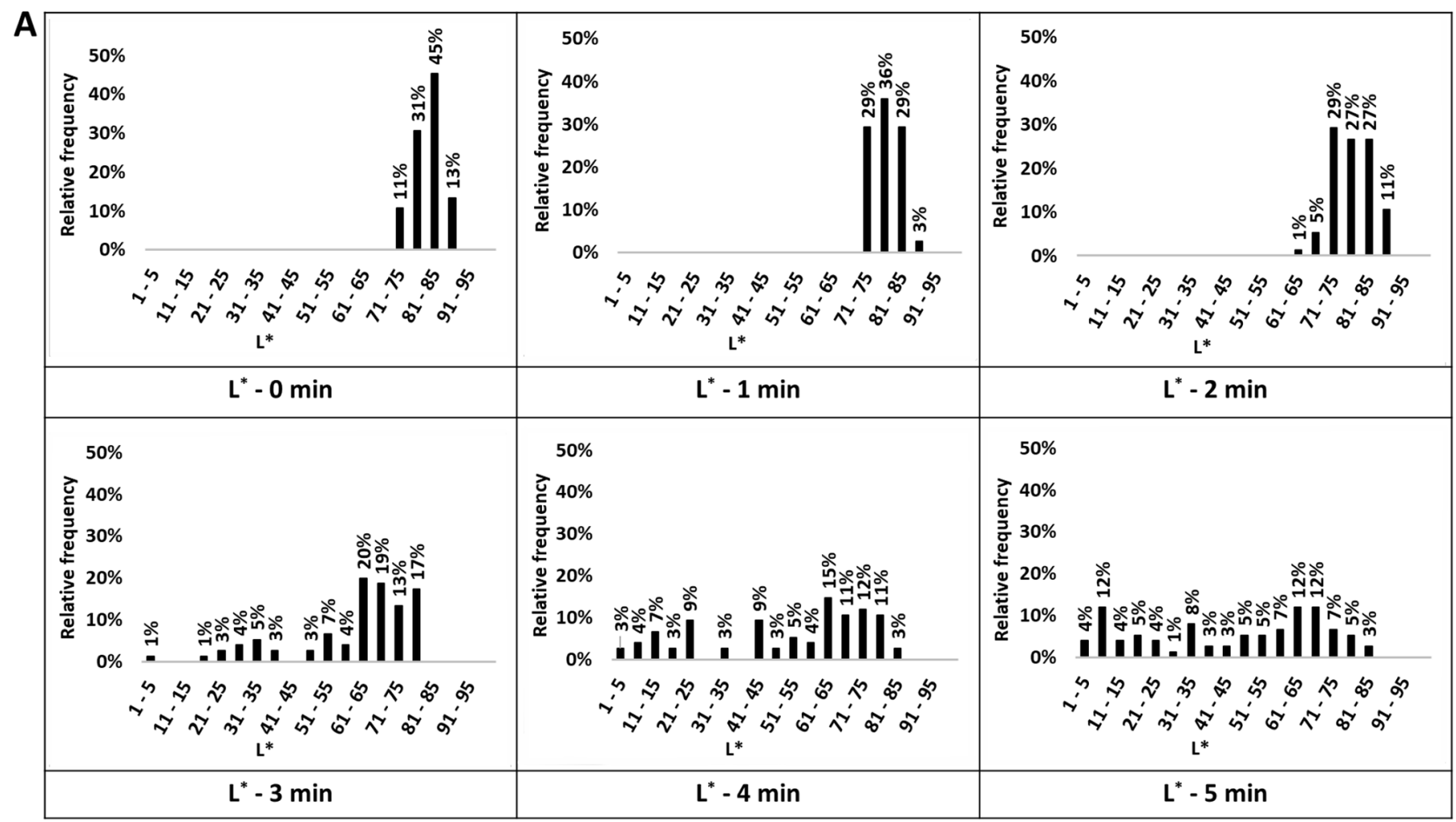

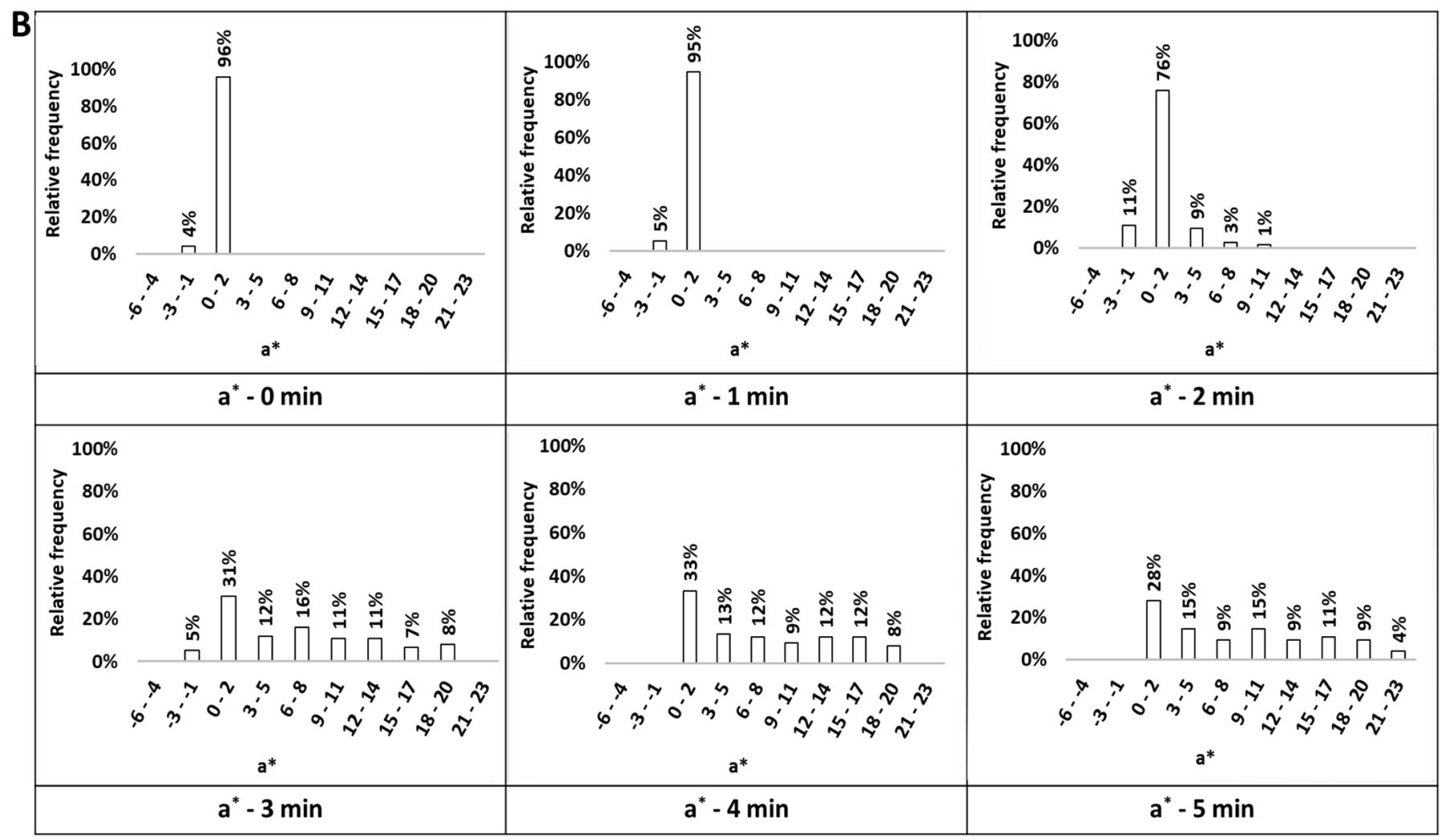

Figure 9. Frequency distribution of L* (lightness; A), a* (red-green color; B), and b* (blue-yellow color; C) values plotted from 3-dimensional Inspector Color analysis of the images obtained for control cheese samples during simulated cheese baking for $0,1,2,3,4$, and 5 min. 


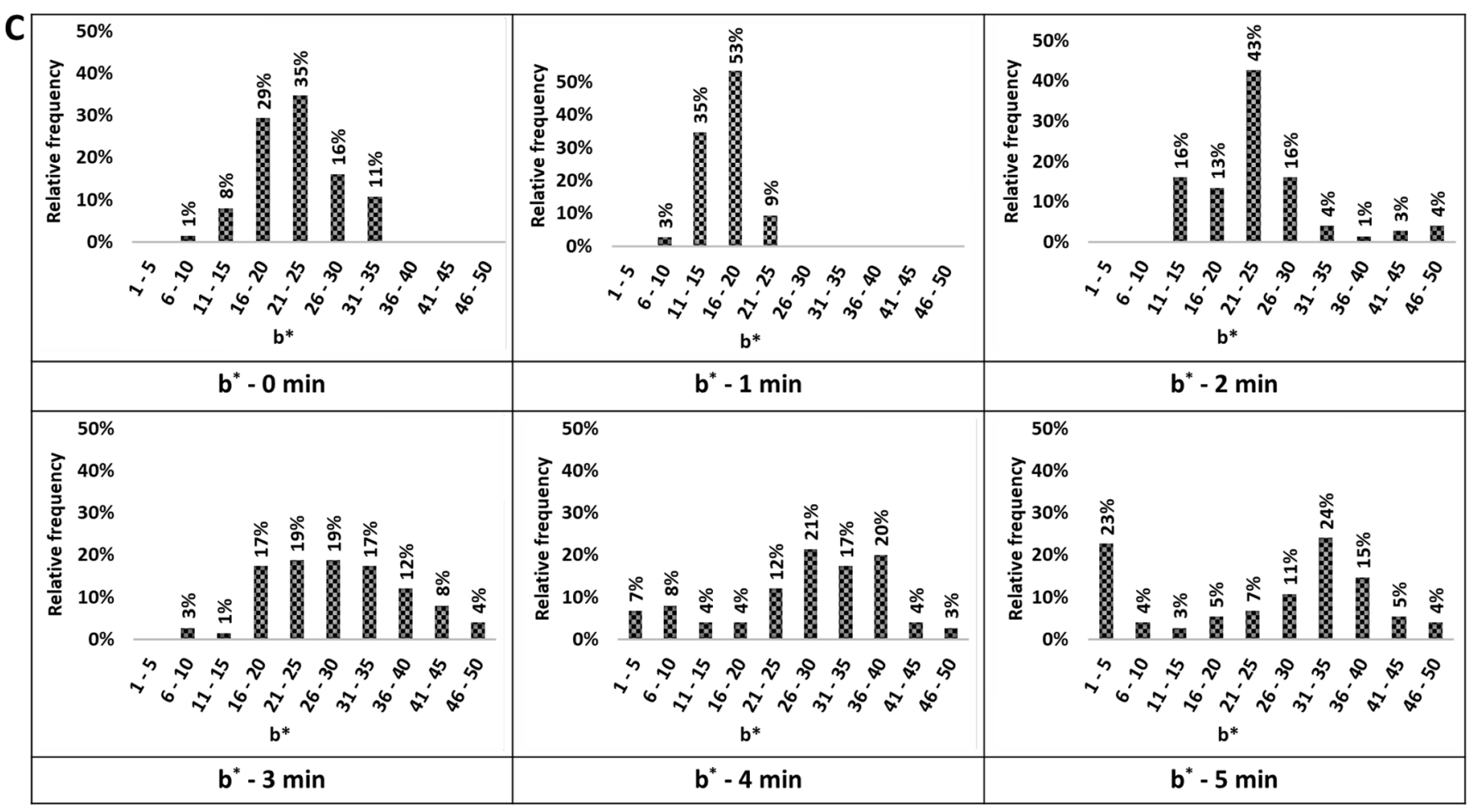

Figure 9 (Continued). Frequency distribution of L* (lightness; A), a* (red-green color; B), and b* (blue-yellow color; C) values plotted from 3-dimensional Inspector Color analysis of the images obtained for control cheese samples during simulated cheese baking for 0, 1, 2, 3, 4, and 5 min.

the SC sample, reaching $100^{\circ} \mathrm{C}$ after $\sim 2$ min of baking time (Figure 7). The SC sample, on the other hand, continued on its path of steady surface temperature increase, taking about $4 \mathrm{~min}$ to cross the $100^{\circ} \mathrm{C}$ temperature (Figure 7). When the temperature of the control sample reached $100^{\circ} \mathrm{C}$, it continued to rise at a faster rate than the temperature of the SC sample. As the surface temperature reached $100^{\circ} \mathrm{C}$, cheese browning was initiated for both the control and SC sample. If the rate of moisture loss at the surface exceeds the rate of moisture migration to the cheese surface, the surface temperature will rise above $100^{\circ} \mathrm{C}$, resulting in browning. The onset of browning for the control sample at 2 min of baking and for the SC sample at 4 min of baking (Figure 6) coincided with the peak in the rate of moisture loss (Figure 5) and the cheese surface crossing the $100^{\circ} \mathrm{C}$ mark (Figure 7 ) at the same time.

As determined in this experiment, the onset of browning time for the $\mathrm{SC}$ sample was $\sim 2$ times greater than the control sample. The SC sample contained $\sim 1.9$ times more moisture (8.34 g of cheese moisture + $7.5 \mathrm{~g}$ of additional water) compared with the control sample ( $8.34 \mathrm{~g}$ of cheese moisture). Assuming a uniform distribution of additional soaked water throughout the sample, the SC sample at the surface would also contain $\sim 1.9$ times more moisture compared with the control sample. Theoretically, based on the equation below, the SC sample at the cheese surface with $\sim 1.9$ times more moisture $(M=$ mass of water) would take an equivalent amount of ( $\sim 1.9$ times $)$ more time to reach $100^{\circ} \mathrm{C}$.

$$
\text { Heating time }=[M(C p \Delta T+L)]+C_{E} / E,
$$

where $C p=$ specific heat of water; $\Delta T=$ water (boiling point temperature - initial temperature at the beginning of heating); $L=$ latent heat of water; $[M(C p \Delta T$ $+L)]=$ heat energy required for the water in cheese; $C_{E}=$ heat energy required for the cheese sample; $E=$ heat energy input rate from the heat source (moisture balance heating element). The amount of cheese used during simulated baking was the same $(15 \mathrm{~g})$ for both the control and SC samples, and hence the heat required for cheese solids was the same for both. The $\Delta T$ for both samples was similar considering initial temperature of the cheese was in the range of 24 to $25^{\circ} \mathrm{C}$ for both samples. The energy input (E) was the same for both samples because they used the same baking temperature and heating element. The time to reach cheese surface temperature at $100^{\circ} \mathrm{C}$ (boiling point of water) for both the control and SC samples coincided 


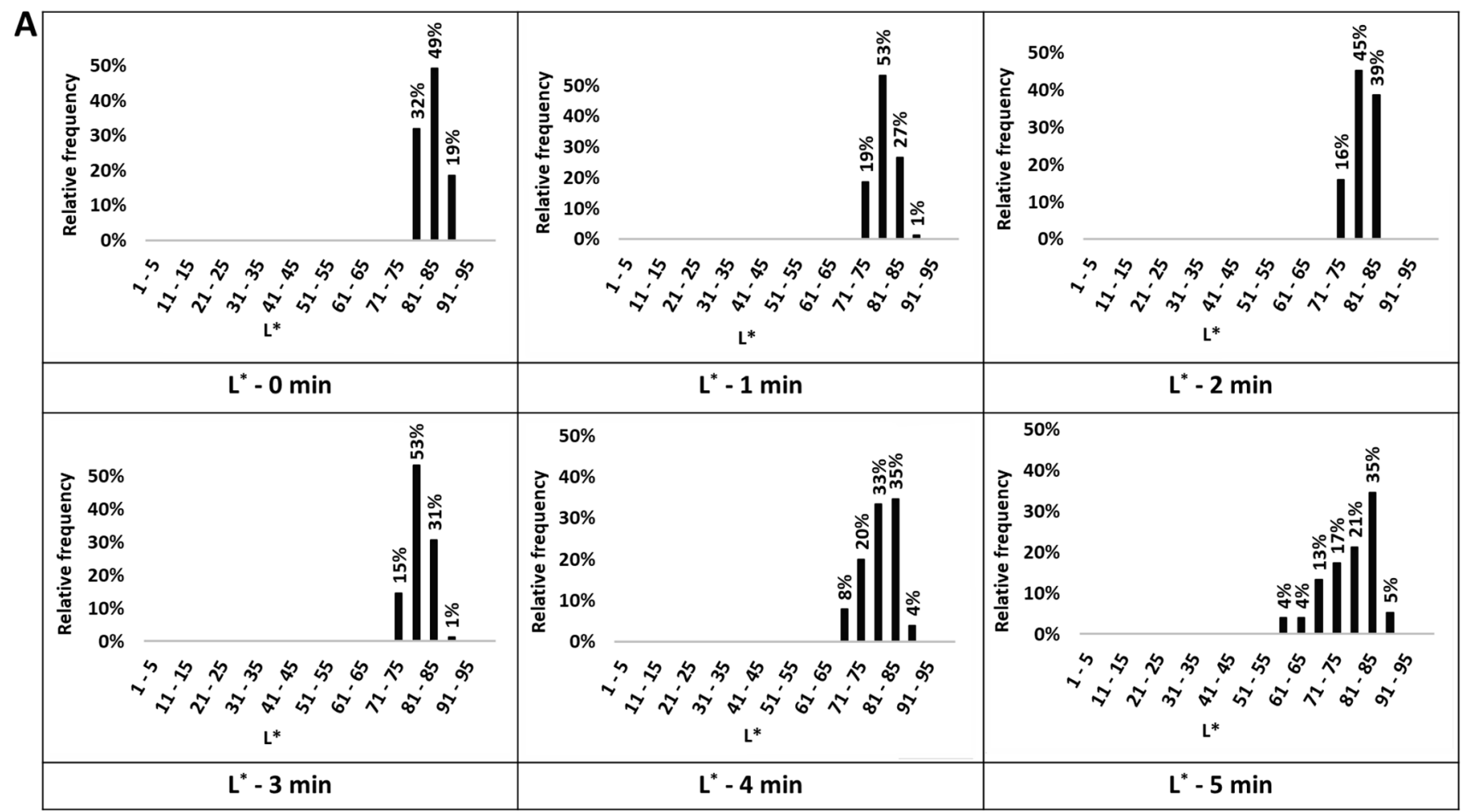

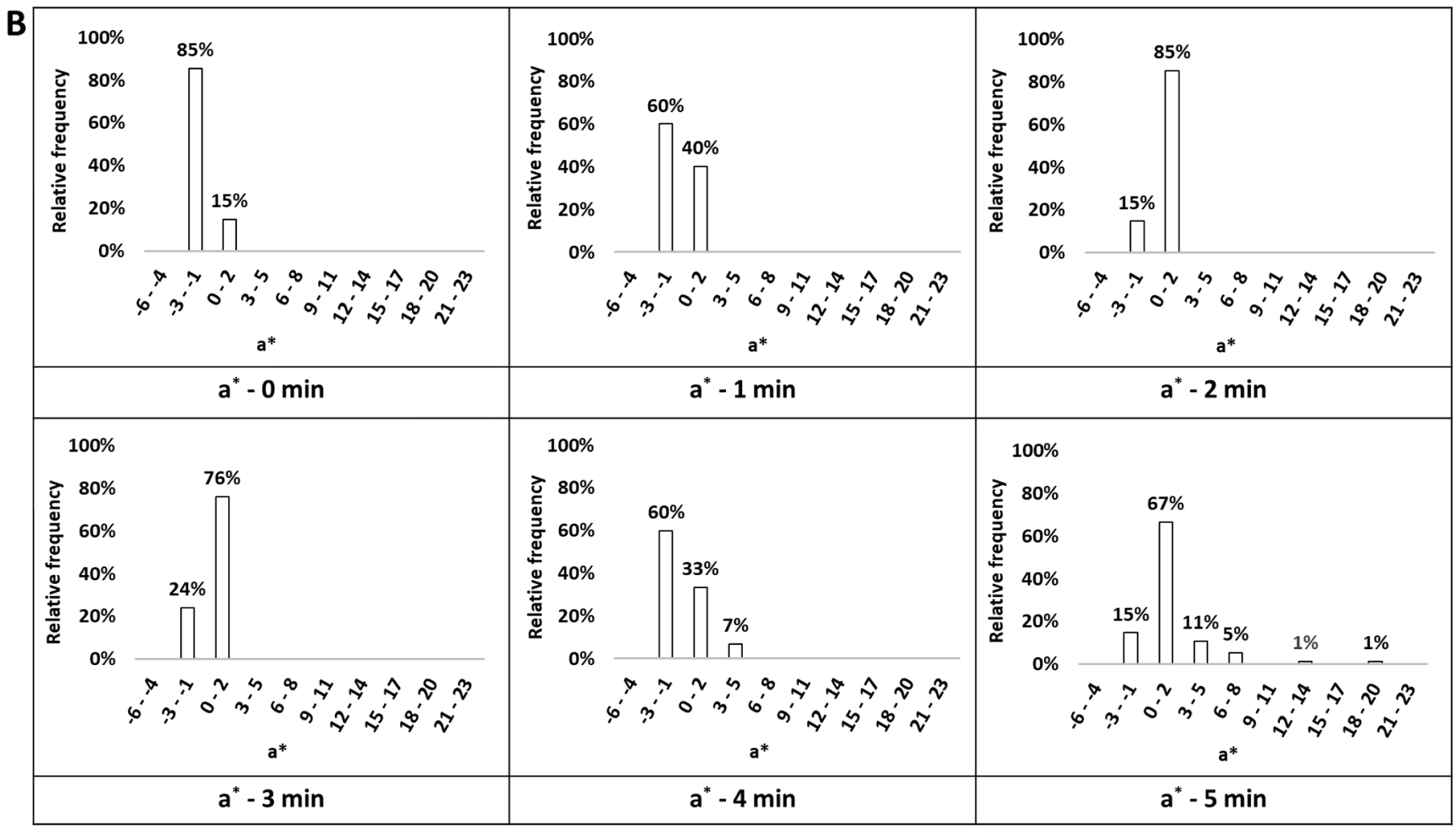

Figure 10. Frequency distribution of L* (lightness; A), a* (red-green color; B), and b* (blue-yellow color; C) values plotted from 3-dimensional Inspector Color analysis of the images obtained for soaked cheese samples during simulated cheese baking for $0,1,2,3,4$, and 5 min. 


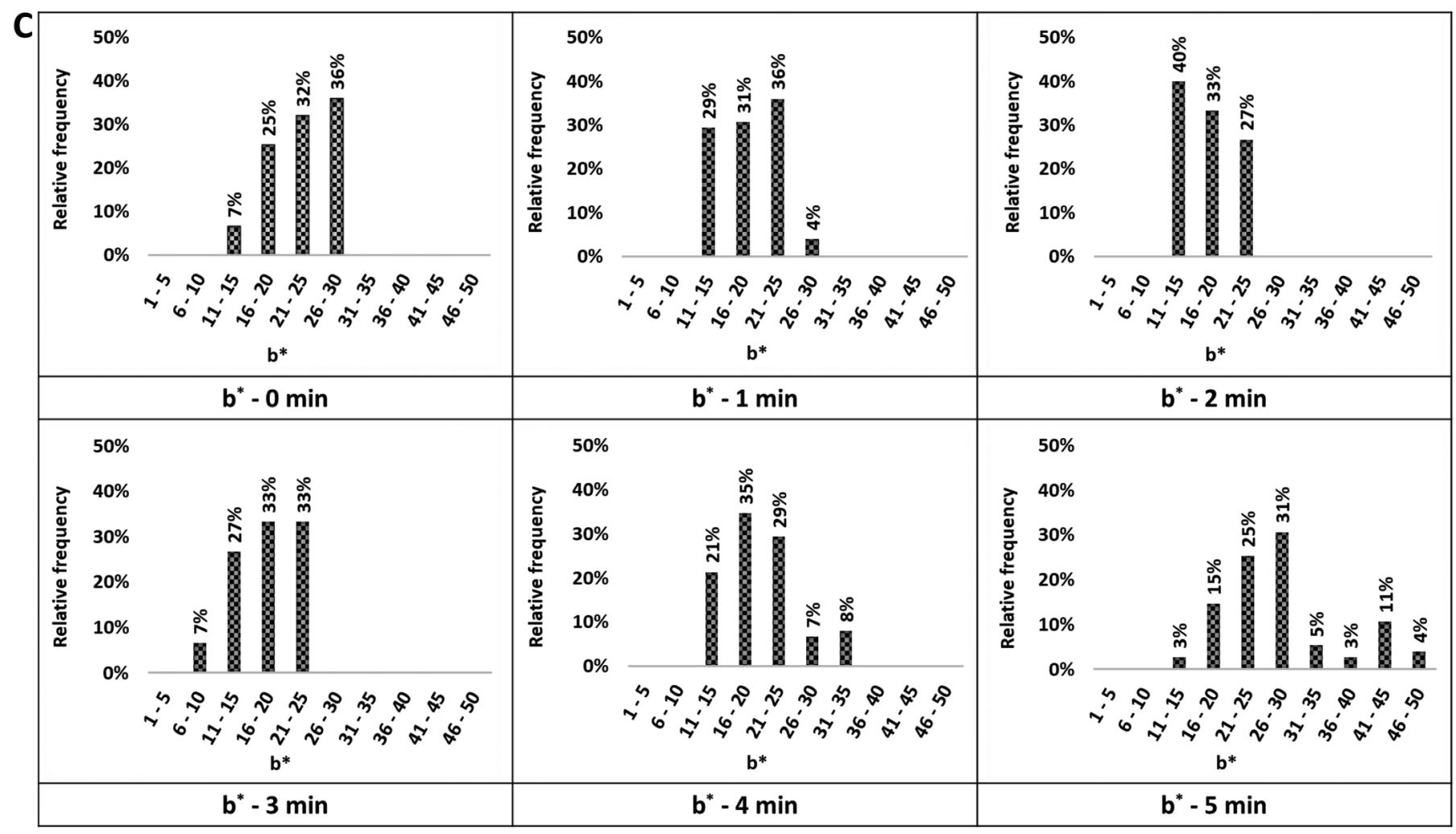

Figure 10 (Continued). Frequency distribution of L* (lightness; A), a* (red-green color; B), and b* (blue-yellow color; C) values plotted from 3-dimensional Inspector Color analysis of the images obtained for soaked cheese samples during simulated cheese baking for 0, 1, 2, 3, 4, and $5 \mathrm{~min}$.

very well with the onset of browning time; thus, this method of measuring cheese surface temperature could be useful in detecting the beginning of cheese browning during bake and applying various tools to control the browning at this point.

\section{Correlation Between 3D Plot CIELAB Color Analysis and Onset of Browning During Simulated Baking}

The CIELAB color space is a 3D cartesian space with 3 mutually perpendicular color coordinates as follows: (1) $\mathrm{L}^{*}$ is the correlate of perceptual lightness; (2) a* is the red $(\mathrm{a}+)$-green $(\mathrm{a}-)$ axis; and $(3) \mathrm{b}^{*}$ is the yellow (b+)-blue (b-) axis (Hernández et al., 2016). Because the rotating image of the $3 \mathrm{D}$ color plot could not be included, we chose 2 images from $\mathrm{L}^{*}$, $\mathrm{a}^{*}$, and $\mathrm{b}^{*}$ color spaces. One image depicts the $\mathrm{L}^{*}$ color space plane, and the other depicts the $\mathrm{a}^{*}$ and $\mathrm{b}^{*}$ color space planes (Figure 8). To interpret the results of these $3 \mathrm{D}$ color plots, frequency distribution charts for $\mathrm{L}^{*}, \mathrm{a}^{*}$, and $\mathrm{b}^{*}$ values were created for both control and SC samples baked at 0, 1, 2, 3, 4, and 5 minutes (Figure 9 and Figure 10).

Overall, the beginning of the shift in frequency distribution of $\mathrm{L}^{*}, \mathrm{a}^{*}$, and $\mathrm{b}^{*}$ values for both control and
SC samples coincided with the onset of browning. For the control sample frequency distribution of the $\mathrm{L}^{*}, \mathrm{a}^{*}$, and $b^{*}$ values at $0 \mathrm{~min}$ of baking were in the frequency range of 71 to $90,-3$ to 2 , and 6 to 35 , respectively (Figure 9). At 2 min of baking for the control sample, the frequency distribution of $\mathrm{L}^{*}, \mathrm{a}^{*}$, and $\mathrm{b}^{*}$ shifted to the 61 to 70,3 to 11 , and 36 to 50 range, respectively (Figure 9). The frequency shift indicated the reduction in lightness and increase in redness and yellowness of the cheese because of onset of browning (Figure 6). Similarly, for the SC sample, the frequency distribution of the $\mathrm{L}^{*}, \mathrm{a}^{*}$, and $\mathrm{b}^{*}$ values at 0 min of baking were in the range of 76 to $90,-3$ to 2 , and 11 to 30 , respectively (Figure 10a-c). At 4 min of baking, the $\mathrm{L}^{*}$, a*, and $\mathrm{b}^{*}$ frequency shifted to 66 to 70,3 to 5 , and 31 to 35 , respectively. These shifts in $\mathrm{L}^{*}, \mathrm{a}^{*}$, and $\mathrm{b}^{*}$ values of the SC sample at 4 min of baking coincided with the onset of visual browning (Figure 6). Colorimeters are commonly used for color analysis of food products, and depending on the type of device used, they can measure the color of a specific type (liquids or powder) or a specific surface area of the sample (solid food products). One of the limitations of these colorimeters for measuring the color change during pizza baking is the limited 
diameter of the measuring probe. This limits the measuring of browning on a pizza in real time as multiple probes would be needed to cover the surface area of the pizza. The software-based image color analysis method could serve as a cost-effective solution to monitor pizza browning during baking.

\section{CONCLUSIONS}

The method of soaking cheese shreds was effective in improving the baking properties of fat-free mozzarella cheese on pizza. During pizza bake with fat-free mozzarella, the SC sample showed satisfactory cheese melt, fusion, and stretch compared with the control sample with substantial shred identity, and poor shred melt, fusion, and stretch. The SC sample also showed desired browning as compared with substantial browning of control sample. Based on simulated pizza baking, both control and SC samples showed a strong correlation between the onset of cheese browning, the peak of moisture-loss rate, and an increase in cheese surface temperature $\left(>100^{\circ} \mathrm{C}\right)$. The color analysis revealed a strong correlation between the onset of cheese browning and a significant shift in $L^{*}$ value toward less lightness, $b^{*}$ value toward more yellowness, and $a^{*}$ value toward redness. These 3 measurement tools (moisture-loss rate, cheese surface temperature, and 3D plot CIELAB color) can be extremely useful in detecting the onset of cheese browning and applying various interventions to control the cheese browning to a desired level. These sensing methods may also be useful in the development of smart ovens.

\section{ACKNOWLEDGMENTS}

We acknowledge Karla Namken (Agropur Dairy Cooperative, Lake Norden, SD) for assistance in operating the conveyor oven. This research was supported by Dairy and Food Science Department, South Dakota State University (Brookings, SD). The authors have not stated any conflicts of interest.

\section{REFERENCES}

Ah, J., and G. P. Tagalpallewar. 2017. Functional properties of Mozzarella cheese for its end use application. J. Food Sci. Technol. 54:3766-3778. https://doi.org/10.1007/s13197-017-2886-z.

Dumas, C., and G. Mittal. 2002. Heat and mass transfer properties of pizza during baking. Int. J. Food Prop. 5:161-177. https://doi .org/10.1081/JFP-120015599.
Fife, R. L., D. J. McMahon, and C. J. Oberg. 1996. Functionality of low fat Mozzarella cheese. J. Dairy Sci. 79:1903-1910. https://doi .org/10.3168/jds.S0022-0302(96)76559-1.

Hernández, B., C. Sáenz, C. Alberdi, and J. Diñeiro. 2016. CIELAB color coordinates versus relative proportions of myoglobin redox forms in the description of fresh meat appearance. J. Food Sci. Technol. 53:4159-4167. https://doi.org/10.1007/s13197-016-2394 -6 .

Kindstedt, P., J. Rippe, and C. Duthie. 1989. Measurement of Mozzarella cheese melting properties by helical viscometry. J. Dairy Sci. 72:3117-3122. https://doi.org/10.3168/jds.S0022-0302(89)79468 -6 .

Ma, X., M. O. Balaban, L. Zhang, E. A. Emanuelsson-Patterson, and B. James. 2014. Quantification of pizza baking properties of different cheeses, and their correlation with cheese functionality. J. Food Sci. 79:E1528-E1534. https://doi.org/10.1111/1750-3841.12540.

Ma, X., B. James, M. O. Balaban, L. Zhang, and E. A. EmanuelssonPatterson. 2013a. Quantifying blistering and browning properties of Mozzarella cheese. Part II: Cheese with different salt and moisture contents. Food Res. Int. 54:917-921. https://doi.org/10.1016/ j.foodres.2013.05.029.

Ma, X., B. J. James, M. Balaban, L. Zhang, and E. A. EmanuelssonPatterson. 2013b. Quantifying blistering and browning properties of Mozzarella cheese. Part I: Cheese made with different starter cultures. Food Res. Int. 54:912-916. https://doi.org/10.1016/j .foodres.2013.06.007.

Merrill, R. K., C. J. Oberg, and D. J. McMahon. 1994. A method for manufacturing reduced fat Mozzarella cheese. J. Dairy Sci. 77:1783-1789. https://doi.org/10.3168/jds.S0022-0302(94)77119 $-8$.

Rudan, M. A., and D. M. Barbano. 1998. A model of Mozzarella cheese melting and browning during pizza baking. J. Dairy Sci. 81:23122319. https://doi.org/10.3168/jds.S0022-0302(98)75812-6.

Sun, D.-W. 2000. Inspecting pizza topping percentage and distribution by a computer vision method. J. Food Eng. 44:245-249. https:// doi.org/10.1016/S0260-8774(00)00024-8.

Wadhwani, R., W. McManus, and D. J. McMahon. 2011. Improvement in melting and baking properties of low-fat Mozzarella cheese. J. Dairy Sci. 94:1713-1723. https://doi.org/10.3168/jds.2010-3952.

Wang, H., and D. Sun. 2003. Assessment of cheese browning affected by baking conditions using computer vision. J. Food Eng. 56:339345. https://doi.org/10.1016/S0260-8774(02)00159-0.

Wang, H.-H., and D.-W. Sun. 2002a. Melting characteristics of cheese: Analysis of effect of cheese dimensions using computer vision techniques. J. Food Eng. 52:279-284. https://doi.org/10.1016/S0260 $-8774(01) 00116-9$.

Wang, H.-H., and D.-W. Sun. 2002b. Melting characteristics of cheese: Analysis of effects of cooking conditions using computer vision technology. J. Food Eng. 51:305-310. https://doi.org/10.1016/ S0260-8774(01)00072-3.

Wang, H. H., and D. W. Sun. 2002c. Correlation between cheese meltability determined with a computer vision method and with Arnott and Schreiber tests. J. Food Sci. 67:745-749. https://doi.org/ 10.1111/j.1365-2621.2002.tb10670.x.

\section{ORCIDS}

S. G. Sutariya @ https://orcid.org/0000-0001-7941-3702

L. E. Metzger (๑) https://orcid.org/0000-0003-3929-4539

G. H. Meletharayil ๑ https://orcid.org/0000-0001-9183-1966 